\title{
Bone Measurements Domain
}

National Cancer Institute

\section{Source}

National Cancer Institute. Bone Measurements Domain. NCI Thesaurus. Code C49566.

A subject domain utilized for the submission of information encompassing and representing data, vocabulary or records related to bone mineral density data. 